\title{
IDENTIFICATION OF POSTAL MAILS AND CRATES BY NEW DEVELOPED UHF RFID ANTENNA
}

\author{
Peter Kolarovszki, Juraj Vaculík, Libor Hofmann \\ University of Zilina \\ Faculty of Operation and Economics of Transport and Communications \\ Department of Communications \\ Univerzitná 1, 010 26, Slovakia \\ Ph.: +421908227492.E-mail: juvac@fpedas.uniza.sk, libor.hofmann@rfidtag.cz, \\ kolarovszki@fpedas.uniza.sk
}

\begin{abstract}
This article deals with RFID technology, which is a part of automatic identification and data capture. We developed a wave propagation model and base on this, we developed a UHF RFID slim antenna. Article describes theoretical background about RFID antennas and electromagnetic waves. Consequently we are coming with the new access, that is, using the UHF RFID "Slim" antenna that eliminates disadvantage of inlays in the case if they are close or inter lap each other. The article describes scheme of identification of postal mails through UHF RFID slim antennas.

Nowadays the identification of postal mails in postal sector is carried through barcodes and optical character recognition. In this article we would like to specify, how can be the postal mail items identified in the transmission process by RFID technology. All theoretical findings are verified by measurement in our AIDC laboratory that is located at the University of Žilina. Finally a method to perform our theoretical model and the identification performance was close $100 \%$. It is an improvement for more than $30 \%$ in comparing the results reached with typical inlays. The results of our research bring the new point of view and indicate the ways using of UHF RFID technology in post applications.
\end{abstract}

Keywords: RFID technology, Transportation, Postal items, propagation model, UHF antenna

\section{Introduction}

RFID technology is one of the most broadly discussed technologies of the past few years. Yet it has not achieved the anticipated commercial expectations.

The main reason is a failure to understand the technology and binding the RFID technology to bar codes, thus marking RFID a "younger brother" to the bar codes. As a result of this erroneous conclusion, the laws of electromagnetic wave propagation were forgotten in many cases. This situation finally led to an incorrect interpretation by the end user; yet, if correctly implemented, great potentialities open for the RFID technology. One of the spheres of RFID application is postal service and monitoring of letters.

Based on recent research results and measurements in the previous period, which were presented at this conference, and last year too, we came to the knowledge that it was necessary to focus on several sub-elements, which significantly influenced readability and thus the quality. These were then designed and tested concerned the theoretical part of their electrical properties and characteristics, and consequently we came to practical tests in the laboratory of automatic identification in the University of Žilina. One of the results of the previous research was to suggest the need for a special identifier for the mail envelope with special focuses to for registered mail and then the verification, which concerned the electrical properties and characteristics and consequently its verification in pilot conditions.

There were several projects how to implement this technology in the past, but the results of identification recognition were not satisfactory.

\section{Theoretical Foundation}

Radio frequency identification is a wireless data collection technology that uses electronic tags, which store data, and tag readers, which remotely retrieve data. It is a method of identifying objects and transferring information about the object's status via radio frequency waves to a host database. RFID is not necessarily a direct replacement for bar codes, but as the costs of RFID systems continue to decrease, the functional utility of RFID will greatly surpass that of bar codes. [6]

An RFID system is a set of components that work together to capture, integrate, and utilize data and information. This section describes some of them. The components are as follows:

- $\quad$ Sensors, Tags, Antennas, Readers.

- Connectors, Cables, Networks, Controllers.

- Data, Software, Information Services. 


\subsection{RFID tags}

An RFID tag is a small device that can be attached to an item, case, container, or pallet, so it can be identified and tracked. It is also called a transponder. The tag is composed of microchip and antenna. These elements are attached to a material called a substrate in order to create an inlay. [7]

Tags are categorized into three types based on the power source for communication and other functionality.

- Active.

- Passive.

- $\quad$ Semi - passive.

- $\quad$ Semi - active.
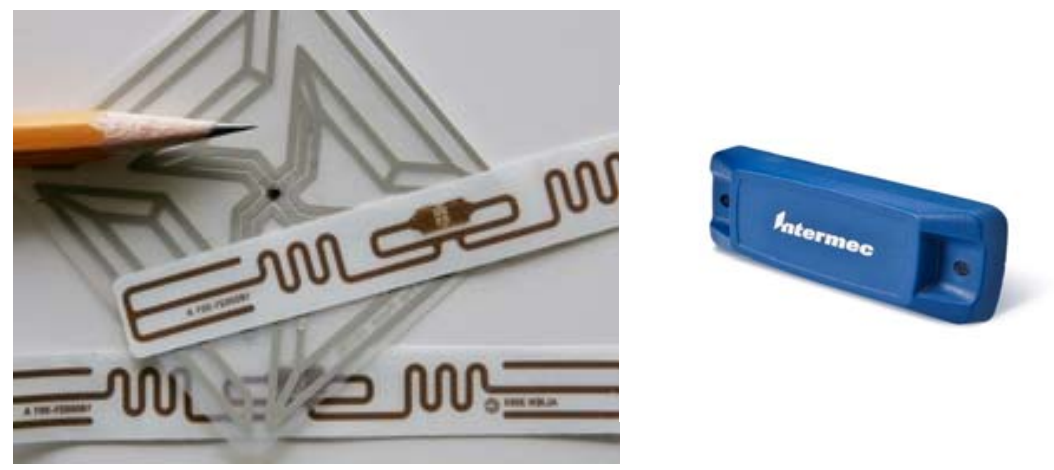

Figure 1. Passive RFID tags

A passive tag (Figure 1) uses the electromagnetic energy it receives from an interrogator's transmission to reply to the interrogator. The reply signal from a passive tag, which is also known as the backscattered signal, has only a fraction of the power of the interrogator's signal. This limited power significantly restricts the operating range of the tag. Since passive tags are low power devices, they can only support data processing of limited complexity. On the other hand, passive tags typically are cheaper, smaller, and lighter than other types of tags, which are compelling advantages for many RFID applications.

An active tag relies on an internal battery for power. The battery is used to communicate to the interrogator, to power on-board circuitry, and to perform other functions. Active tags can communicate over greater distance than other types of tags, but they have a finite battery life and are generally larger and more expensive. Since these tags have internal power, they can respond to lower power signals than passive tags.

A semi-active tag is an active tag that remains dormant until it receives a signal from the interrogator to wake up. The tag can then use its battery to communicate with the interrogator. Like active tags, semi- active tags can communicate over a longer distance than passive tags. Their main advantage relative to active tags is that they have a longer battery life. The waking process, however, sometimes causes an unacceptable time delay when tags pass interrogators very quickly or when many tags need to be read within a very short period of time.

A semi-passive tag is a passive tag that uses a battery to power on-board circuitry, but not to produce return signals. When the battery is used to power a sensor, they are often called sensor tags. They typically are smaller and cheaper than active tags, but have greater functionality than passive tags because more power is available for other purposes. Some literature uses the terms "semi-passive" and "semiactive” interchangeably.

\section{Functionality}

- The primary function of a tag is to provide an identifier to an interrogator, but many types of tags support additional capabilities that are valuable for certain business processes. These include:

- Memory - memory enables data to be stored on tags and retrieved at a later time. Memory is either write once, read many (WORM) memory or re-writeable memory, which can be modified after initialization. Memory enables more flexibility in the design of RFID systems because 
RFID data transactions can occur without concurrent access to data stored in an enterprise subsystem. However, adding memory to a tag increases its cost and power requirements.

- Environmental sensors. The integration of environmental sensors with tags is an example of the benefit of local memory. The sensors can record temperature, humidity, vibration, or other phenomena to the tag's memory, which can later be retrieved by an interrogator.

- Security functionality, such as password protection and cryptography. Tags with on-board memory are often coupled with security mechanisms to protect the data stored in that memory. For example, some tags support a lock command that, depending on its implementation, can prevent further modification of data in the tag's memory or can prevent access to data in the tag's memory. In some cases, the lock command is permanent and in other cases, an interrogator can "unlock" the memory.

- Privacy protection mechanisms. EPC tags support a feature called the kill command that permanently disables the ability of the tag to respond to subsequent commands. Unlike the lock command, the kill command is irreversible. The kill command also prevents access to a tag's identifier, in addition to any memory that may be on the tag. While the lock command provides security, the primary objective of the kill command is personal privacy [1].

\subsection{RFID Reader}

The second component in a basic RFID system is the interrogator or reader (Figure 2). Readers can have an integrated antenna, or the antenna can be separate. The antenna can be an integral part of the reader, or it can be a separate device. Handheld units are a combination reader/antenna, while larger systems usually separate the antennae from the readers. The reader retrieves the information from the RFID tag. The reader may be self-contained and record the information internally; however, it may also be part of a localized system such as a POS cash register, a large Local Area Network (LAN), or a Wide Area Network (WAN). [5]

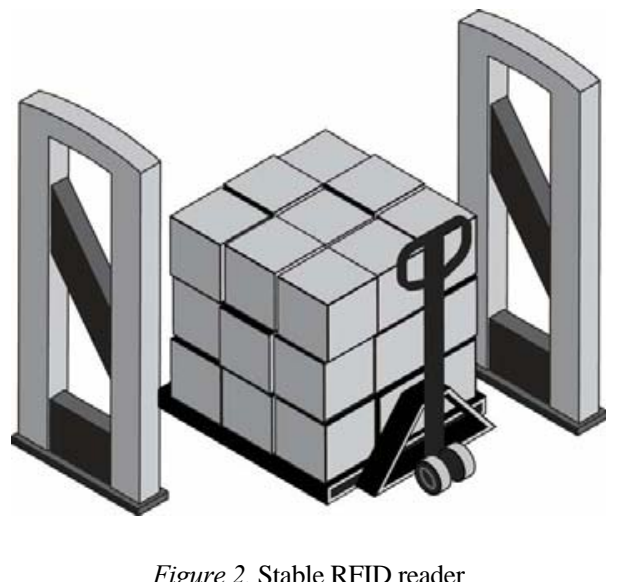

There is also Middleware, software that controls the reader and the data coming from the tags and moves them to other database systems. In our cases we have used the Aton AMP middleware. It carries out basic functions, such as filtering, integration and control of the reader. RFID systems work, if the reader antenna transmits radio signals. These signals are captured tag, which corresponds to the corresponding radio signal.

\subsection{Basics of Electromagnetic for Antennas}

The submitted solution introduces a new approach to identification of letter post; it is based on a development of a UHF RFD antenna with a slenderness coefficient 2000, which leads to a significant increase of identification reliability on a $99.9 \%$ level.

These basic specifications were specified for solving the problem:

- dimensions of the transport box

- number of letters in one transport box

- $\quad m$ reading distance in a UHF RFID tunnel, with the reader power 2W/ERP

- $\quad$ reaching a reading recognition on a level higher than $99 \%$.

Critical factor: mutual shielding of RFID tags (antennas) with a failure in their identification. 
The existing tests and solutions of postal consignment identification utilized various versions of RFID inlay. Naturally, the most economical solution is searched for.

Each UHF RFID inlay is basically a dipole, which is located on an underlay substrate of a specified permittivity. Logically, all inlays are designed so they their range is as long as possible. In agreement with the radiolocation equation it is essential that the UHF RFID inlay antenna should be as large as possible and able to intercept the largest possible amount of EM energy and, conversely, be able to transmit energy as great as possible back to the transmitters.

$$
l=\sqrt[4]{\frac{P t x * C * K * A^{2}}{160 \pi^{2} * \operatorname{Pr} x * \lambda^{2}}}
$$

$I$ is the distance of the antenna from the target, $P t x$ is the transmitting power, $C$ is a constant given by the nature of the target (design of the tag), $A$ is the area of the receiving antenna, $k-$ a constant given by the type of the antenna (3-10), Pr $x$ is the received power.

As it is clear from the formula, a radical increase of the range can be achieved by a change of the antenna's area or a wave length rather than a change of the transmitting power. Since the wave length and the maximum power in RFID are determined, we can work with only one variable, which is the antenna's area.

To make it more complicated, the input circuit of the UHF RFID chip is nonlinear and its impedance changes with the power and frequency. You can find details on this problem in a bulletin.

To utilize the UHF RFID antenna for postal services, it is necessary to find an optimum solution for the area of the antenna and the defined critical factor, i.e. the likelihood of mutual shielding of the antennas. Even if the antennas are mutually shielded, the maximum identification must still be maintained. The first basic step lies in a calculation of the power balance.

\section{Budget calculation}

Free space path loss

$F S P L=92.4+20 \log D[\mathrm{~km}]+20 \log F[\mathrm{GHz}]$

$F S P L=92.4+20 \log 0.001+20 \log 0.867=-31.16 d B$

Free-space path loss in $1 \mathrm{~m}$ with no other obstructions or propagation issue is $-31.16 \mathrm{~dB}$

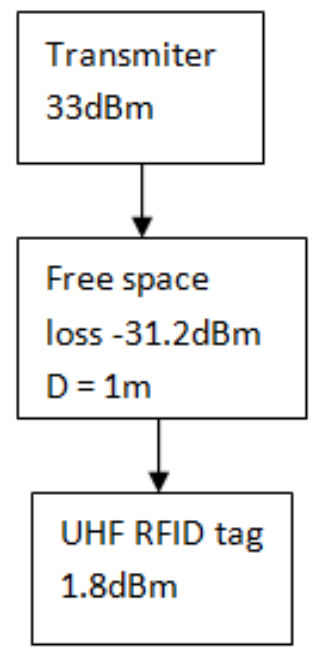

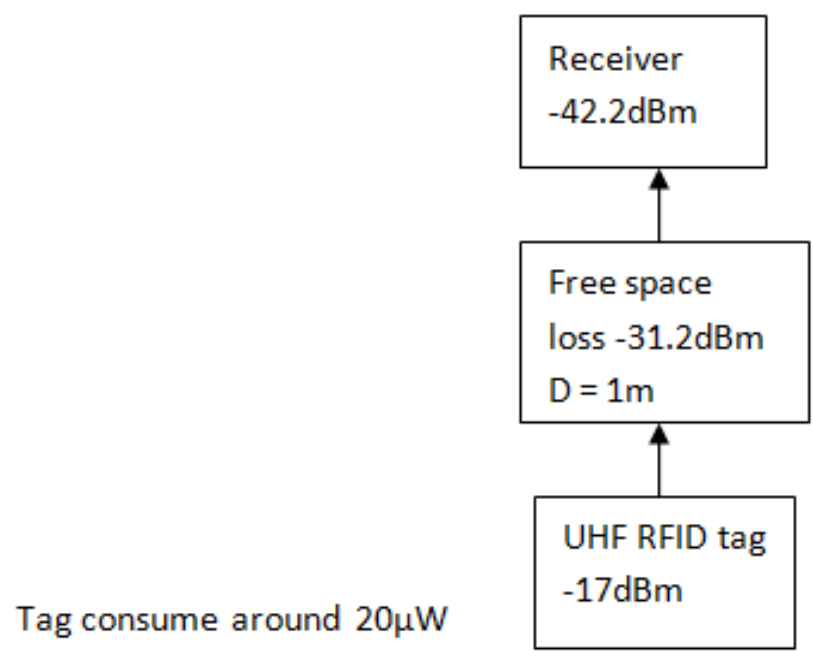

Figure 3. Free-space path loss

The antenna's important parameter is the effective aperture $A e$. It must be noted that $A e$ is not a physical area of the antenna or its part. It is part of the space from which a particular antenna can receive power of an electromagnetic wave. The dimensions of a classic dipole are $3 / 4 \lambda * 1 / 4 \lambda$, i.e. the dipole $A e$ is $0.13 \lambda^{2}$; for the RFID frequency of $867 \mathrm{MHz}$ the value equals $155 \mathrm{~cm}^{2}$ 


\section{Definition of the radiated power density}

In the task, we determined the reading distance as one meter, which is the centre of a manipulation box containing letter post. The section area of a 470x270x260 mm box is $1,222 \mathrm{~cm}^{2}$.

$$
A e=G\left(\frac{\lambda^{2}}{4 \pi}\right) .
$$

$A e$ is effective aperture; $\lambda$ is wave length and the gain $G$ i.e. measured relative to an isotropic antenna in $d B i$.

Ae for a dipole (tag) is

$$
A e_{T}=\left(\frac{0.34^{2}}{4 \pi}\right)=90 \mathrm{~cm}^{2} \text {. }
$$

Ae for UHF reader antenna

$$
A e_{T R}=6 *\left(\frac{0.34^{2}}{4 \pi}\right)=361 \mathrm{~cm}^{2} .
$$

The Ae parameter plays a big role, if we have a group of antennas operating on an identical frequency, located close to each other - this is the case of the letter post. In an ideal distribution of antennas, the individual effective apertures should not be shielded and each antenna should receive EM energy from its space. If the antenna is to receive the maximum energy, it must not be shielded and no materials absorbing EM energy should lie near it.

Ideally, based on the $A e$ value, the transport box should contain no more than $1220: 90=14$ envelopes. However, we need to monitor fifty envelopes in one box.

\section{Simulation}

Figure 4 illustrates simulation of two antennas $15 \mathrm{~cm}$ apart, i.e. without mutual Ae shielding.

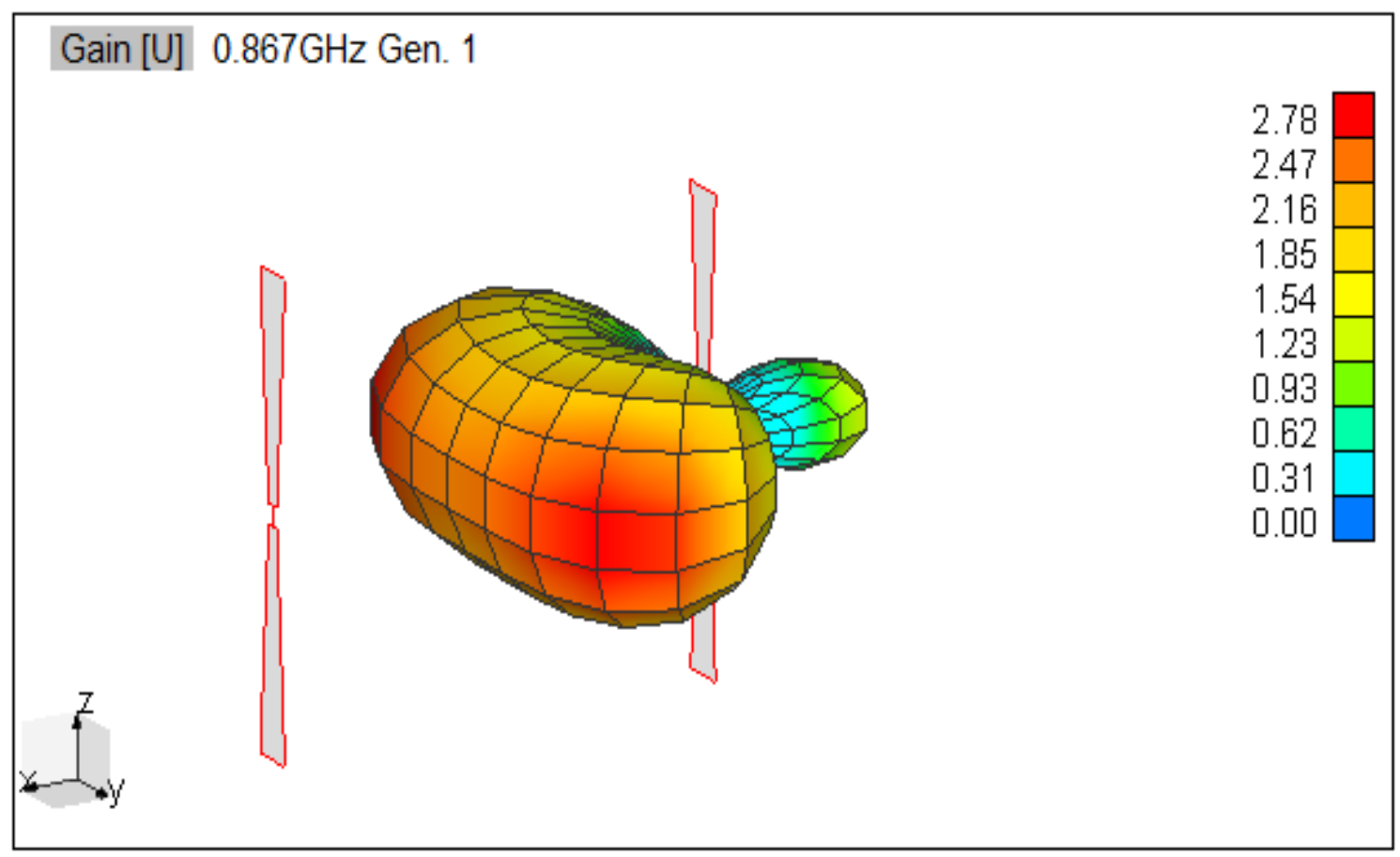

Figure 4. UHF RFID inlays, apart $15 \mathrm{~cm}$

Figure 5a, 5b illustrates simulation of two antennas only one centimetre apart, which corresponds to a likely distribution of envelopes in a transport box. The selected position of the antennas corresponds to the worst situation where the antennas shield each other. We used a dipole $10 \mathrm{x} 1 \mathrm{~cm}$ in the simulation 


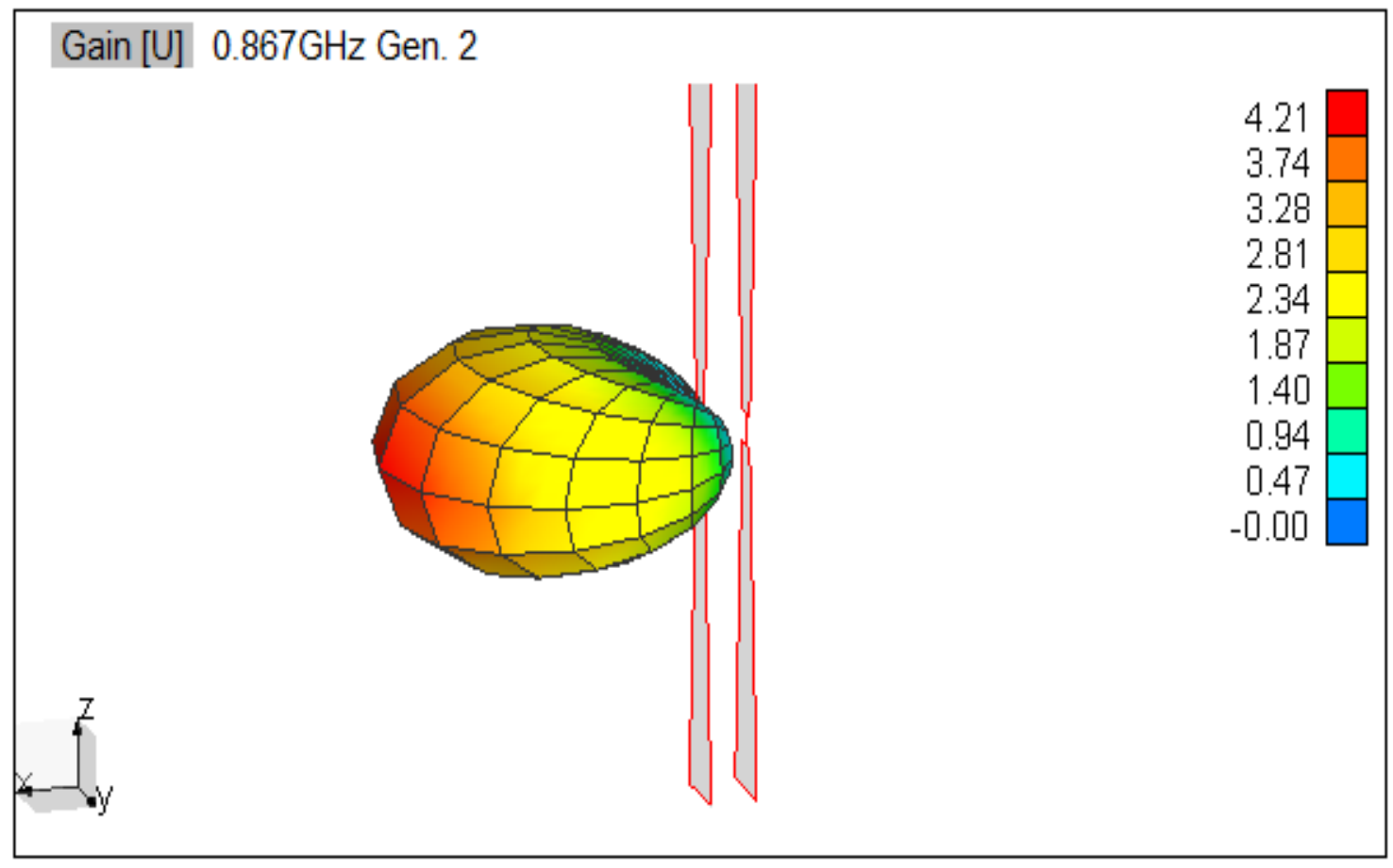

Figure 5a. UHF RFID inlay number 1, apart $1 \mathrm{~cm}$

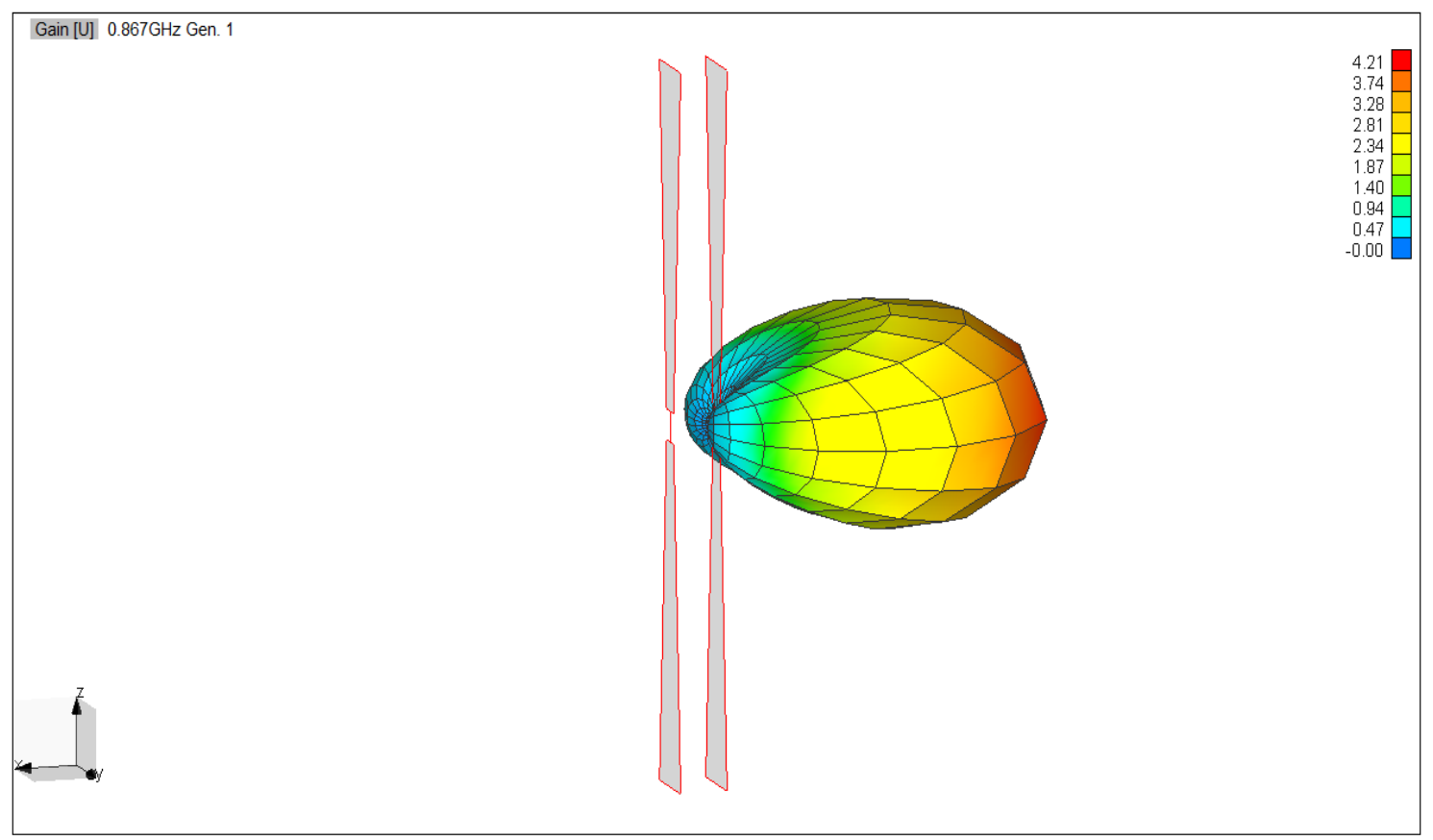

Figure 5b. UHF RFID inlay number 2, apart $1 \mathrm{~cm}$

We can conclude from the calculation of power balance that the amount of power for the RFID chip is sufficient for optimising the antenna. The optimising task involves minimization of mutual interaction of antennas, thus ensuring maximum reading reliability. The theory of probability allows us to calculate the mutual shielding likelihood of at least two antennas by more than $50 \%$ from the entire set of antennas in the defined space of the transport box. To reduce the likelihood of the antennas' mutual shielding, we must reduce the size of the antenna. We chose a dipole with a slenderness coefficient 1,600 in our design. With the reduced dimensions, we reduce the usable area of the antenna and the reading distance (see equation (1)), but we simultaneously increase the quality factor of the antenna and reduce 
the band. With regard to the power budget, reduction of the area represents no problem. We can use a number of optimising tools.

Figure 6 illustrates simulation of our antenna with a coefficient 1,600.

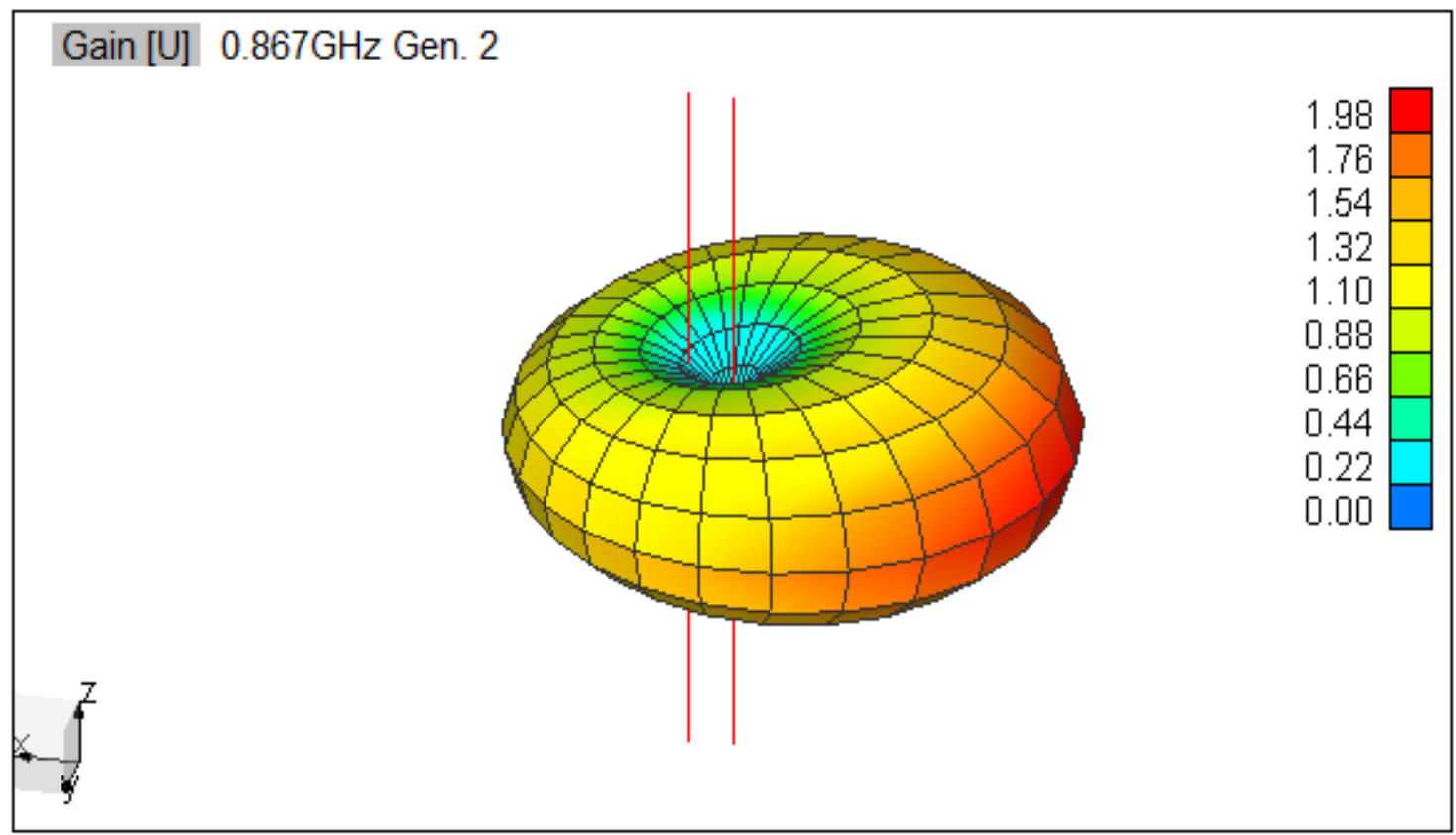

Figure 6. Antenna with a coefficient 1,600

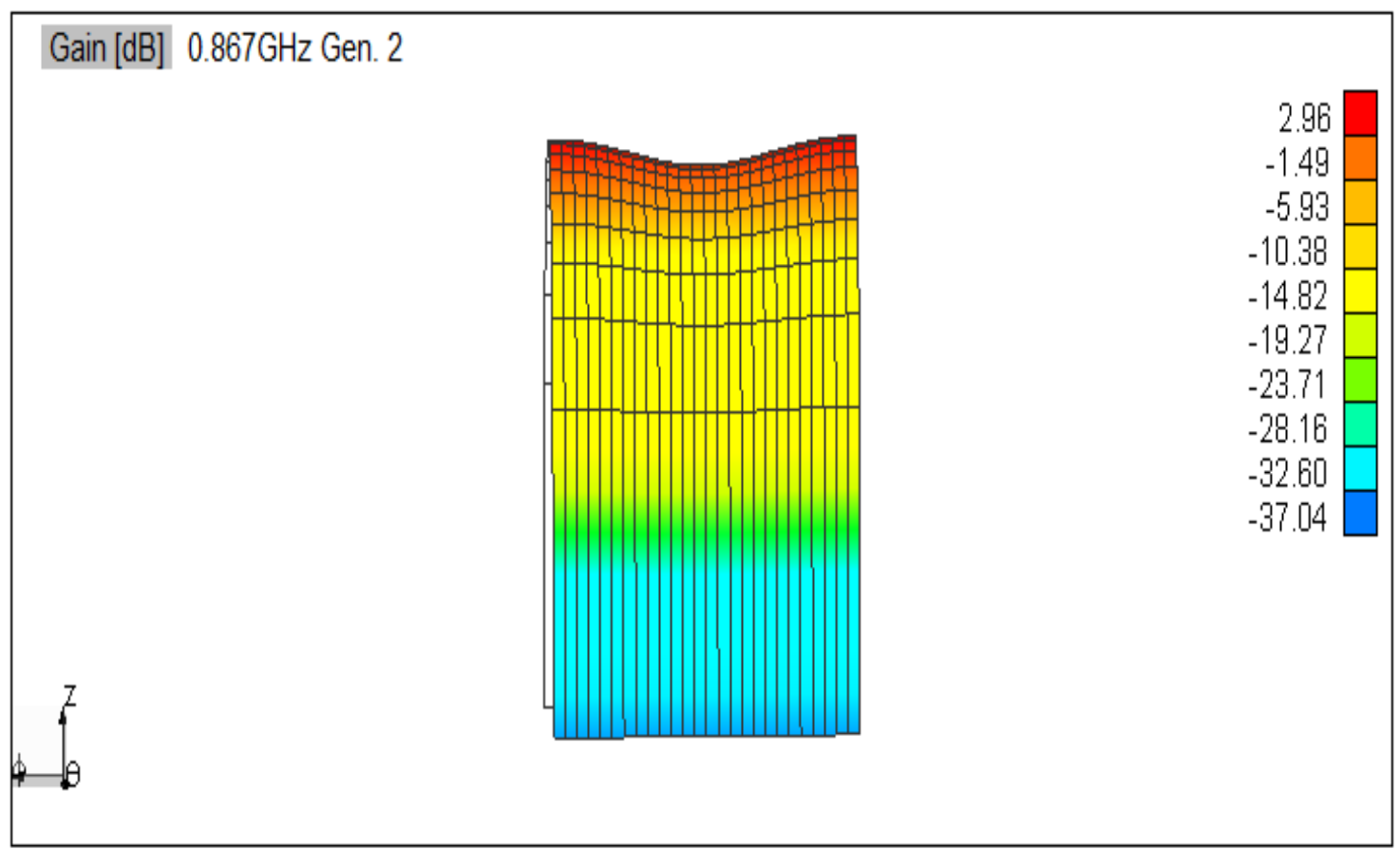

Figure 7. Radiation pattern (cartesian) - our solution

The results of the simulation Figure 7 show that even if the distance between the antennas is short, the other antenna, which is shielded, can be read thanks to the antenna's high slenderness coefficient. In addition, the design of the antenna reduces the likelihood of mutual shielding by more than 50\% compared to a classic inlay. Figure 8 illustrates that second inlay is impossible read if the distance between the antenna is $1 \mathrm{~cm}$. 


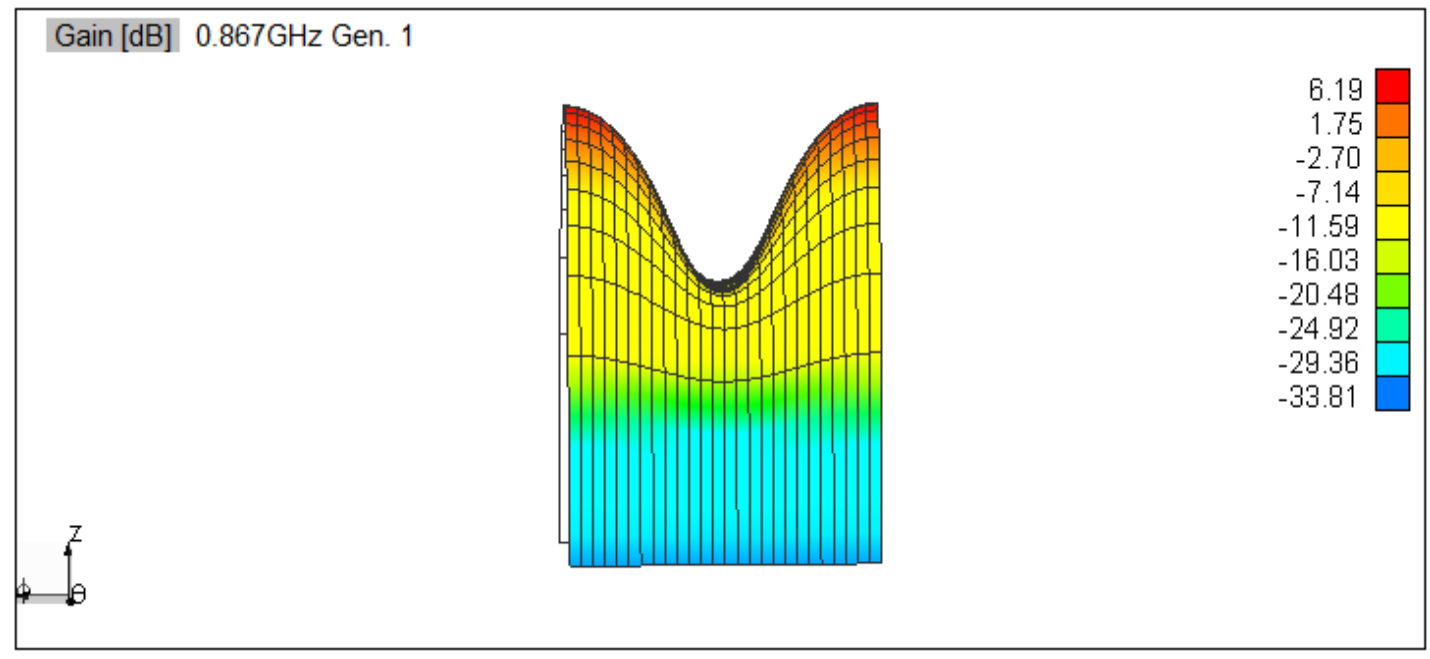

Figure 8. Radiation pattern (cartesian) - inlay

\section{Practical Verification}

One of the methods that could significantly make the process of identifying the postal items in transport condition effective is just a RFID technology. As a wireless technology, without visual contact with the shipment, it tracks and identifies the contents without the need of manual handling from the crate. This allows easier and more efficient handling of supporting documents (creating the list of items, checking the presence of item) of postal sacks/bags and containers.

With the opportunity to perform testing in a laboratory conditions relatives the operation environment, it got an opportunity to take measurements and evaluate the reliability of reading multiple items in the crate. To simplify and automate this activity the web application has been created a. This application is able to communicate with Aton AMP middleware on the level of inserting and updating data into database. For creating the application was used scripting language PHP and hypertext mark-up language. The visual formats enable Cascading Style Sheets and relational database management system MySQL serves as a repository of data. Designed web application allows you to define the measurement parameters, manage, filter, store and present the results of the measurements. Graphic site of application and images was made in the commercial graphics program Adobe Photoshop. For writing and the ease of reference in the source code was used editor Notepad ++.

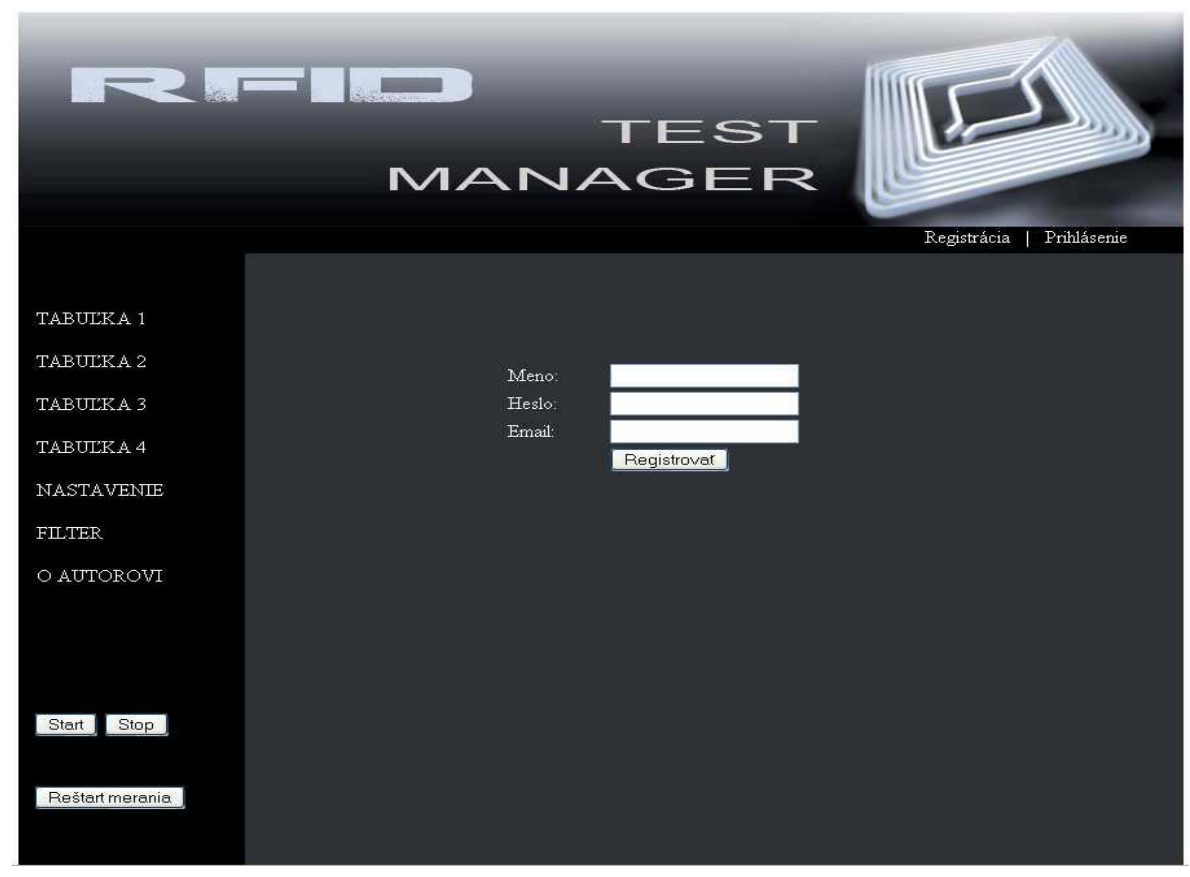

Figure 9. Web application 


\subsection{Description of web application and configuration model}

As can be seen in the figure above the main page is visually divided into three basic parts the header, menu and content. To allow the user to work fully in the application must complete and submit the registration form and then sign. By the registration should be indicated name, password and email. After logging in to the application, the user should see ten items in the menu, such as:

- Table 1 - hold out comprehensive information about the tags which was recorded by the reader namely: tag identification, summary of all specific tags, and type of measurement, rate and RSSI (Received signal strength indication);

- Table 2 - Just inform the ongoing measurement of its serial number, the time when it took, place of the crates to the antenna position, signal strength and the loading of each tag is always the last transition of crates by RFID gates;

- Table 3 - contains only 2 columns. The first shows the number of measurement and the second the total number of downloading within each measurement;

- Table 4 - displays detailed information about the number of tags in a carte, reported in each measurement, what is critical for test of success and the optimal location of the tag on envelope;

- $\quad$ setting - by clicking on the item the user has available form to set parameters of the incoming type of measurement appropriate a large number of different combinations;

- filter - item needed to filter the huge amount of information in the database (after the first measurement there was more than 15,000 lines). Data can be sorted by several parameters. Based on user selection table may be stored in a database or displayed within the content of the web application;

- $\quad$ authors - item is used to view basic information about the author of the application;

- $\quad$ start and stop - buttons for the start and end of testing. For all tables in the application by pressing the START also activates automatically refresh pages at one-second intervals. Click STOP to end measurement and stops refresh;

- restart measurement - after reaching a certain number of measurements, recording data automatically terminated and for the restart is necessary restart the measurement. Click to the button a serial number of measuring returns to 1

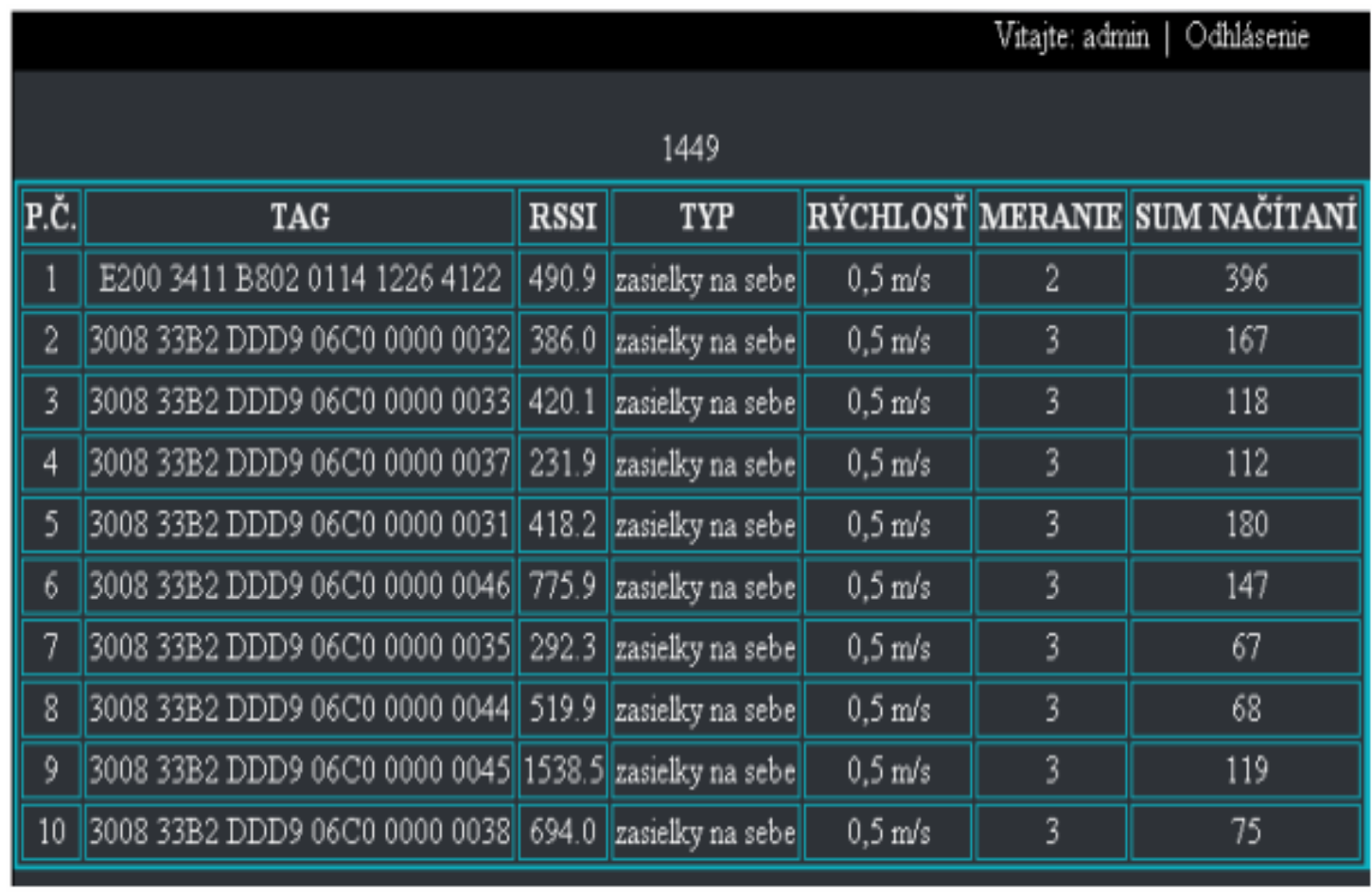

Figure 10. Screen from the web application 


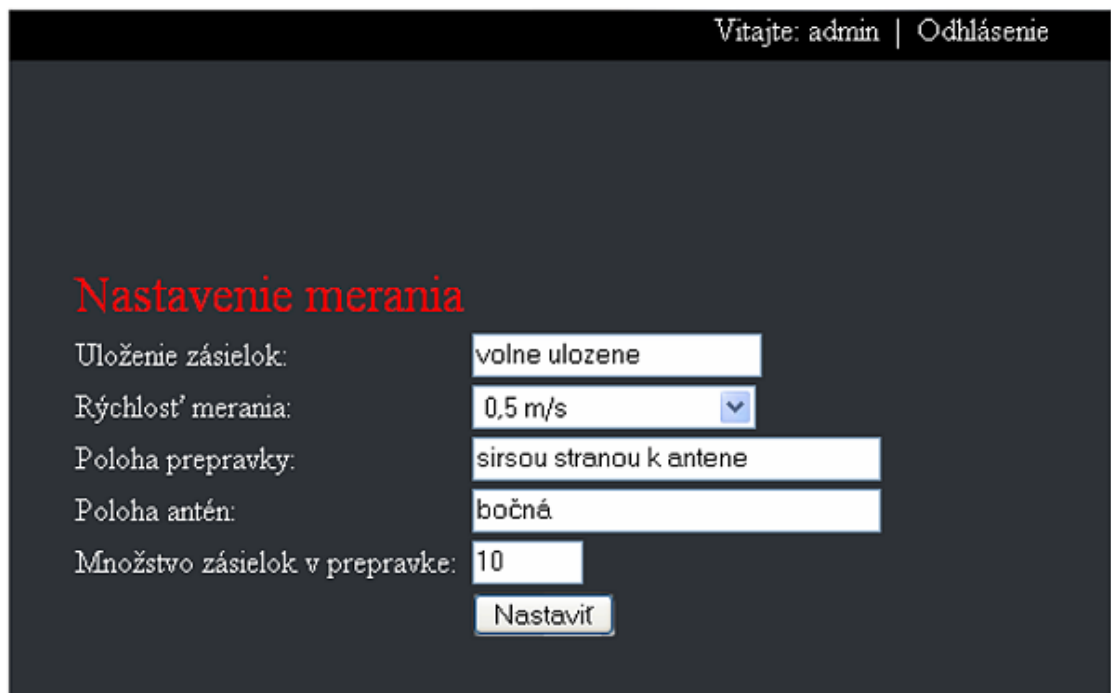

Figure 11. Settings your own measurement

On Figure 12 the configuration can be seen that has been done in middleware AMP. AMP is software from Italian company Aton, also known as a middleware, which provides the management, organizational and communication operations between different applications. In our case, they are the firmware Alien Gate and other applications, particularly database server. AMP itself is not a monolithic program, but it is a functional connection Java service console (java server) and the graphic manager called Qflow.

The configuration consists of several processors (from Alien Device through inline select Processors, databases, filter equals and of course insert processor save).

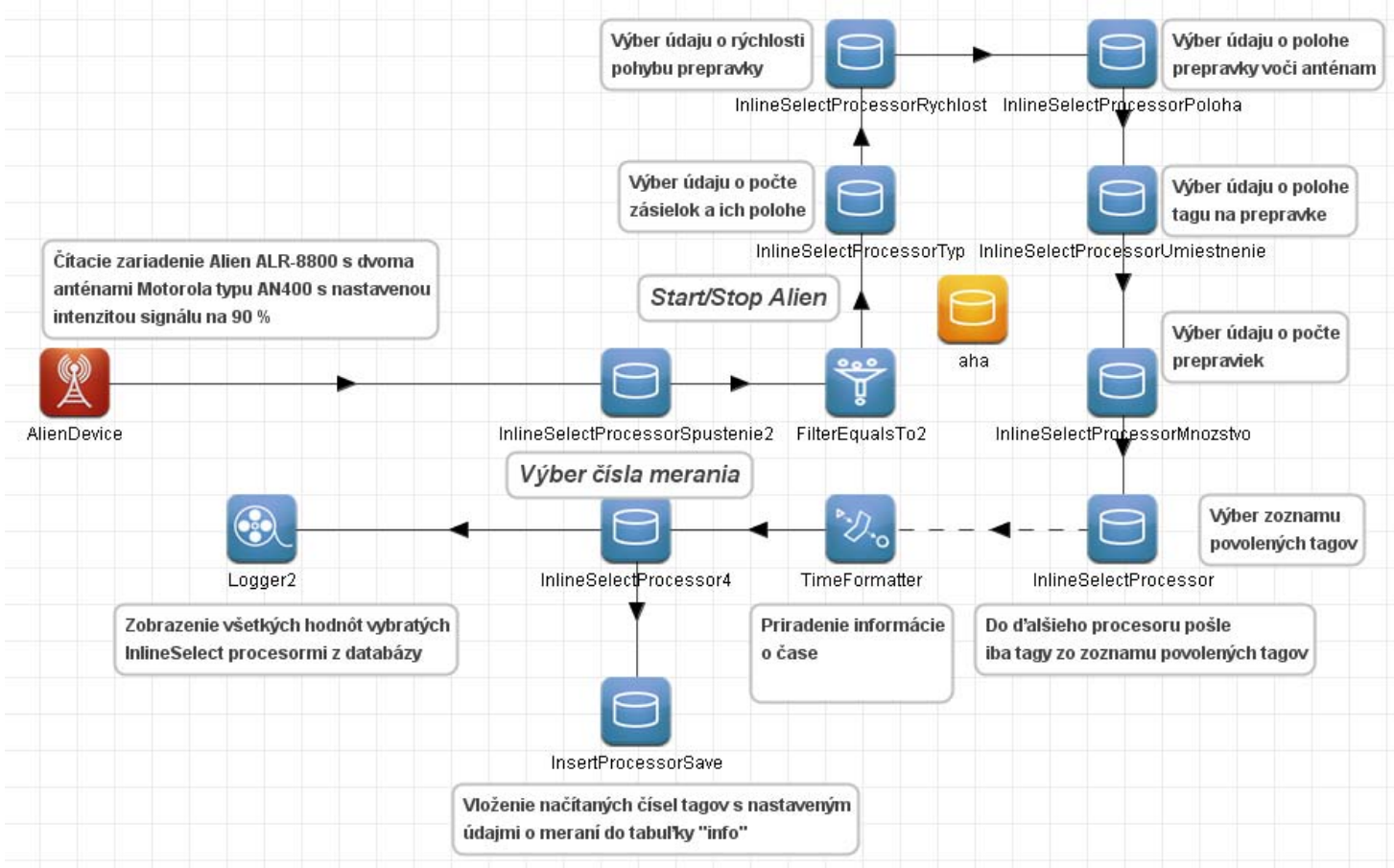

Figure 12. Configuration model in middleware AMP

\subsection{Proposal transport packages and test items for testing}

Packaging material is now immediate and hardly substitutable importance. It provides protection of commercial value of the goods against the adverse effect of environment on the way from sender to recipient. Typical examples are pollution, vibration, shock, and the like. 


\section{Mailing envelopes of bubble wrap}

This type envelope is used for transmission of sensitive goods. Its base is solid craft paper, which is lined inside double-layer polyethylene film. It provides reliable protection products against bumps and shocks due to air cushion are crimped inside the envelope. Equally important features are light weight and convenient self-adhesive closure. Bubble envelope has insulating properties, providing protection against moisture and abrasion. They have a wide range of uses, but they are used primarily for transporting fragile items (electronics, jewellery, perfumes, etc.). For measuring bubble envelope were used in three dimensions:

- $\quad$ big 34 x 24,5 cm - 20 pieces

- $\quad$ middle 27,5 x $20 \mathrm{~cm}-10$ pieces

- small 22,5 x $14 \mathrm{~cm}-5$ pieces

All envelopes containing a special RFID tag, whose electrical properties was described in the introduction.

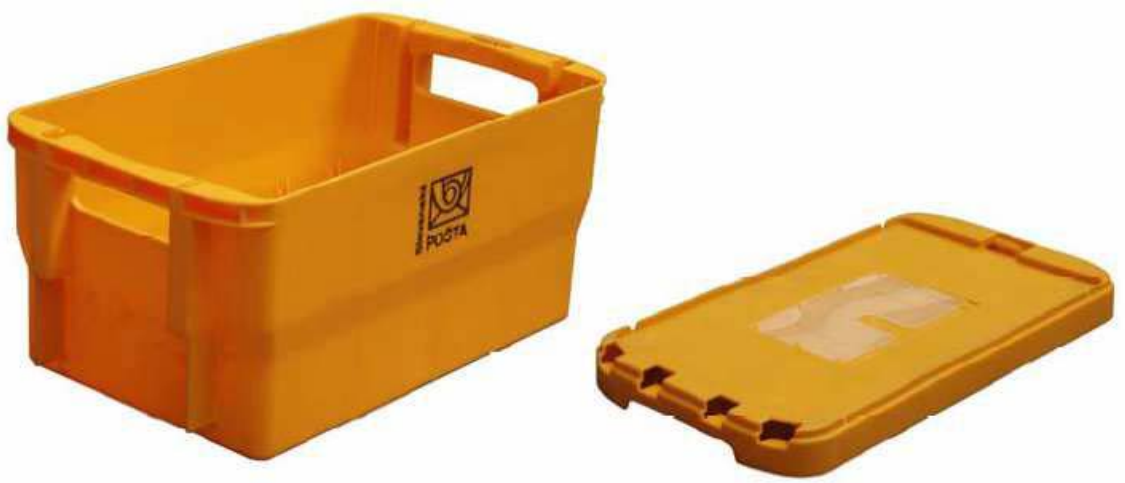

Figure 13. Special postal crate

\subsubsection{Test items under optimal conditions}

For review set out six factors affecting the readability of mail were carried out 26 experiments with 600 measurements. Based on the results obtained to assess the relevance of each effect and make an attempt to set the optimal conditions described in Table 1.

Table 1. Setting the optimal conditions for testing items

\begin{tabular}{|c|c|}
\hline Factor & Optimal setting \\
\hline Method of deposit items in the crate & $\begin{array}{l}\text { Shipments standing side by side with the flat side toward the } \\
\text { side antennas }\end{array}$ \\
\hline Speed of crate & $0,5 \mathrm{~m} / \mathrm{s}$ \\
\hline Type of mail order packaging & Medium-sized envelopes of bubble wrap \\
\hline Number of items in the crate & 10 \\
\hline Location of antennas & Antennas placed on the sides of linear line \\
\hline
\end{tabular}

Table 2. The readability of tags at optimal conditions

\begin{tabular}{|c|}
\hline $\begin{array}{c}\text { Terminal four digits } \\
\text { identification number of tag }\end{array}$ \\
\hline 0031 \\
\hline 0032 \\
\hline 0033 \\
0035 \\
0037 \\
0038 \\
0043 \\
0044 \\
0045 \\
0046 \\
\hline
\end{tabular}

\begin{tabular}{|c|}
$\begin{array}{c}\text { The number of successful measurements/ total } \\
\text { number of measurements }\end{array}$ \\
\hline $20 / 20$ \\
$17 / 20$ \\
$20 / 20$ \\
$20 / 20$ \\
$20 / 20$ \\
$20 / 20$ \\
$20 / 20$ \\
$19 / 20$ \\
$20 / 20$ \\
$20 / 20$ \\
$\mathbb{1 9 , 6 / 2 0}$ \\
\hline
\end{tabular}

\begin{tabular}{|c|c|}
\hline $\begin{array}{c}\text { The success of } \\
\text { reading }\end{array}$ & $\begin{array}{c}\text { The total } \\
\text { number of } \\
\text { reading }\end{array}$ \\
\hline $100 \%$ & 277 \\
\hline $85 \%$ & 131 \\
\hline $100 \%$ & 173 \\
\hline $100 \%$ & 316 \\
\hline $100 \%$ & 346 \\
\hline $100 \%$ & 229 \\
\hline $100 \%$ & 170 \\
\hline $95 \%$ & 161 \\
\hline $100 \%$ & 286 \\
\hline $100 \%$ & 186 \\
\hline $\mathbf{9 8} \%$ & $\mathbf{2 2 8}$ \\
\hline
\end{tabular}


The results of measurements carried out under optimal conditions show very favourable values of all tests that have been realized. The average readability was $98 \%$, while only two of them were unsuccessful recording. Failure to achieve $100 \%$ readability of shipments can be attributed the intensity of the reading device, which had to be set at $90 \%$ level in order to ensure proper functioning of the system for measuring and recording results.

\section{Conclusions}

RFID technology is still growing up and there are several types of application, which you can use in condition of the logistics and postal processes, etc. applications in SCM, mail bag, letter trays, roll cages and vehicle tracking application. Most postal services provide at least a limited form of track and trace, particularly for premium delivery services. Today, tracking uses bar codes. Switching to RFID tags can lower tracking labour by eliminating the need for most manual piece handling.

This article deals with the scheme of identification of postal mails through new developed UHF RFID slim antenna. During the tests of success postal items detection in a laboratory environment, we achieved good results with items from the bubble wrap, but these values were not sufficient for immediate application of technology in real operation.

Prospective opportunities and encouraging laboratory results are a good reason to continue the test measurements. In other experiments, it would be appropriate to focus on improving the switching of individual measurements, which would be established based on RFID reader, but as the principle of photocells.

Alternatively, it can be implemented to the current system some elements of metal barrier that would fulfilled the function of shielding between the two readers. This would avoid the interference and signal strength of reader could be set to $100 \%$.

Since the most of measurements carried out with ten items is necessary to be aware that compliance with the crates to one-third of their storage capacity, although in real operation possible, but highly unlikely and mostly ineffective. For testing full capacity of postal crate (30 and more postal items inside the crate) would be desirable to operate a reader Motorola XR 480, which can connect up to 4 antennas simultaneously. Article is part of the projects described below, which, together with the aforementioned application, will improve the learning process at the Department of Communications.

\section{References}

1. Hunt, V. D., Puglia, A., Puglia, M. (2007). RFID: A Guide to Radio Frequency Identification. Hoboken, NJ, USA: John Wiley \& Sons.

2. Švadlenka, L. (2007). RFID in postal and courier services. In Ed. by Prasad, B. V. S., Kalai, S. Supply Chain Management in Services Industry: an introduction, $1^{\text {st }}$ edition (pp. 68-74). Hyderabad (India): Icfai Books.

3. Thornton, F., RFID Security, Rockland Syngres Publishing 2006. ISBN 1-59749-047-4.

4. Tengler, J. (2010). Identification of postal items through RFID technology. Diploma work. University of Žilina, Žilina, the Slovak Republic.

5. Zelik, P. (2010). Mobile technology in postal transport. Dissertation work. Faculty of Economical and Operation of Transport and Communication, University of Žilina, the Slovak Republic.

6. Kolarovszki, P., Vaculík, J. (2010). Real process of automatic identification items and services and transfer of knowledge - RFID LAB. In Pošta, Telekomunikácie a Elektronický obchod. [online].

7. Poirier, Charles, (2006). RFID Strategic Implementation and ROI: A Practical Roadmap to Success. J. Ross Publishing, Inc.

8. Myerson, Judith M. (2007). RFID in the Supply Chain: A Guide to Selection and Implementation.

9. Michálek, I., Vaculík, J. (December 2008). RFID planning levels for postal and courier services. In Future Role of Postal Services in the Face of New Market Conditions and Communication Technologies: Monograph (Chapter 23). Pardubice, the Slovak Republic: University of Pardubice.

10. Finkenzeller, K. (2006). Fundamentals and Applications in Contactless Smart Cards and Identification. In RFID Handbook. New York: John Wiley \& Sons.

11. Lehpamer, H. (2008). RFID Design Principles. Norwood, MA, USA: Artech House, Inc. 
This contribution/publication is the result of the project implementation:

Centre of Excellence for Systems and Services of Intelligent Transport II ITMS 26220120050 supported by the Research \& Development Operational Programme funded by the ERDF.

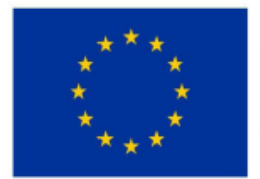

Európska únia

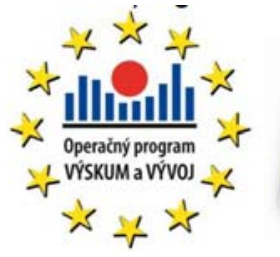

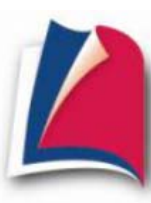

Agentúra

Ministerstva školstva, vedy, výskumu a športu SR pre štrukturálne fondy EÚ

VEGA 1/0687/11 "Assessment of the Business Excellence status" 